\title{
Assessment of Bridge Substructure in Java Island
}

\author{
Pringga Satria Panj1 1,*, Tommy Ilyas², and Erly Bahsan ${ }^{2}$ \\ ${ }^{1}$ Graduate Student, Civil and Environmental Engineering, University of Indonesia \\ ${ }^{2}$ Lecturer, Civil and Environmental Eengineering Department, University of Indonesia
}

\begin{abstract}
Bridges play important roles in transportation system. Hazard to substructure of bridges become amplified. Based on previous year data, at least one-third of total bridges in Indonesia are damaged in certain level of defect. The performance of existing bridges shall be in-check everytime. Substructure of bridge itself is prone to hazards such as ground displacement, slope instability, seismic-related hazard and scour. Traffic data and soil investigation data will be used to analyse ground displacement and slope instability where the bridge located. Local geological and seismic data will be used to assess seismic-related hazard. Quantitative data is technical information and analyses from geotechnical aspects. Qualitative data is an expert system collected from bridge expert and local goverment. The expert system will have a rating system for each aspect. Fuzzy-based method is an effective tool for modeling some vague datas and this ease the decision-making process. Fuzzy Analytical Hierarchy Process (FAHP) will be used to analyses geotechnical aspect and expert system. Hazard identification, risk rating, risk analysis, and risk assessment are steps conducted in FAHP method. Classification and rating of risk can be done with proposed method. This assessment can be a tool or recommendation for local government where the bridge located.
\end{abstract}

\section{Introduction}

In a road network system, bridges play an important role as a complementary road infrastructure. Bridges can be the backbone of infrastructure that links one region to another (Andric et al, 2015). Bridges can connect road that is separated by rivers, lakes, ravines, valleys, straits, highways and railways. In its development, the bridge undergoes the evolution from wooden and simple stone bridges to bridges with more complex structural systems and advanced materials. The advanced materials used in more complex bridge structure (such as concrete, steel and cables) that continue to develop will encourage the construction of bridges with more complex technology than ever before.

In Indonesia, Directorate General of Highways of Ministry of Public Works and Housing (Dirjen Bina Marga Kementerian PU-PERA) is responsible for bridge management through archipelago. The Directorate General of Highways uses the Bridge Management System (BMS) for more systematic monitoring and planning of the bridge. The BMS developed and owned by the Directorate General of Highways serves as a tool for the process of storing bridge-related data; such as design work, construction, rehabilitation and monitoring of bridge condition. For the purposes of the bridge survey, Indonesia's Directorate General of Highways has a Working Unit of Planning and Supervision of National Roads and located in each province.
According to data collected from the Ministry of Public Works and Housing Statistics Information Book (Buku Informasi Statistik Kementerian PUPERA) year 2015 , the total number of bridges in Indonesia recorded by the Ministry per year 2014 is 14710 bridges with various conditions. Here are the details of the bridge conditions recorded:

- Good condition: 6609 bridges (45\%)

- Medium condition: 3137 bridges (21.3\%)

- Lighty-damaged condition: 3253 bridges (22.1\%)

- Heavily-damaged condition: 1360 bridges (9.2\%)

- Critical condition: 314 bridges (2.1\%)

- Collapse / break-up: 37 bridges (0.3\%)

- Total bridges recorded: 14710 bridges

From the data above, the condition of the bridge in Indonesia is composed of various conditions, ranging from good conditions until the condition of collapsed or broke. The bridges listed above are bridges that have been designed and built by the Directorate General of Highways. Those bridges have various shaping materials with varying length and spans.

When reviewed from the number of bridges with damaged conditions (light, heavy and critical damage), then the percentage of bridges with damaged condition

\footnotetext{
* Corresponding author: pringgas@gmail.com, pringga.satria61@ui.ac.id
} 
in Indonesia is about $33.4 \%$ of the total bridges. Approximately one-third of bridges in Indonesia are in damaged condition. From this condition, the bridge maintenance and monitoring system have to be evaluated. Good systems, wise decision makers and sufficient funds will be able to reduce the percentage of damaged bridges in Indonesia. Decision makers (central and local government) play an important role in the care and monitoring of bridge conditions.

Assessment process to determine the current state of the bridge can be done by collecting various related data and then those data can be analyzed and generate a value that will be able to assist in the decision-making process. Related research on the structure of the bridge (such as deck, frame and bridge pier or pier) has relatively much research on it. Research on the assessment of the substructure of bridge is not as much as upper-structure of bridges. Damage to upper and lower structures of jembaatan will result in disruption of the service life of the bridge.

Use a two-column format, and set the spacing between the columns at $8 \mathrm{~mm}$. Do not add any page numbers.

\section{Literature Study}

To evaluate sub-structure condition of a bridges, several methods can be conducted. Then, after evaluation process, assessment process shall be done. In this paper, assessment process is done by Fuzzy Analytical Hierarchy Process (Fuzzy AHP). Fuzy AHP is based on fuzzy set that is developed by Lotfi Zadeh in 1965. The result of Fuzzy AHP is rating of each criterion. Rating that is respected to value of each criteria is the result of assessment process. Based on the rating, decision making can be done with those rating.

In this paper, evaluation criteria will be described based on text book. Slope stability, ground movement and Fuzzy AHP will be described below.

\subsection{Basic Concept of Slope Stability Evaluation}

According to Duncan and Wright (2005), the process of slope stability evaluation needs to be done to determine the safety factor of a slope. Clear and comprehensive evalution results should also be done for the following reasons:

- Evaluation results should be checked by a few engineers and experts from relevant institutions. Multiple examinations are intended to minimize errors that may occur during the evalution process and to gain a different perspective on a problem.

- Evalution results must be clear and understandable by the client

- Responsibility for engineering evalution results is usually given to engineers at an institution or company. The engineer must understand the results of the evaluation and understand the basis of the decisions taken in the analysis and evaluation.

- Evaluation results should be well documented. Good documentation will make it easier if the data at any time required in the future.

It is inevitable that each slope location evaluated has different characteristics from one another. In Java, soil conditions in each province will be different. Geological detail plays an important role in slope stability, and for that, geological information of a region is very important (Duncan \& Wright, 2005). Then, the next step in the evaluation of the stability of the slope is the evalution of the soil property. Evaluation of soil properties will be closely related to geotechnical investigations. Geotechnical investigation work will include field and laboratory work. The properties obtained are quite diverse, among others are: property of soil shear strength, soil stiffness, soil physical characteristics and others. In slope stability, shear strength parameters and soil density are prioritized.

Pore water pressure also plays an important and critical role in the evalution of slope stability. Normally, pore water pressure (PWP) analysis is based on the groundwater level obtained through the information in the bor-log or piezometer measurement test. The boundary conditions also need to be specified in the PWP analysis. If necessary, seepage analysis is required to determine the behavior of pore water movement or flow. Flow charts or PWP contours and total heads need to be displayed and clearly documented during the PWP analysis process.

Occasionally, some slopes have special features that affect slope stability, such as the addition of slope reinforcement. Slope reinforcement can be soil nails, geogrid, geotextile, anchor, pile and other types of reinforcement. Basically, the addition of slope reinforcement is intended to increase the value of the safety factor (FS). Details on slope reinforcement should be well documented in an effort to evaluate slope stability. The final result of slope stabilization is slope geometry, land property and FS final value.

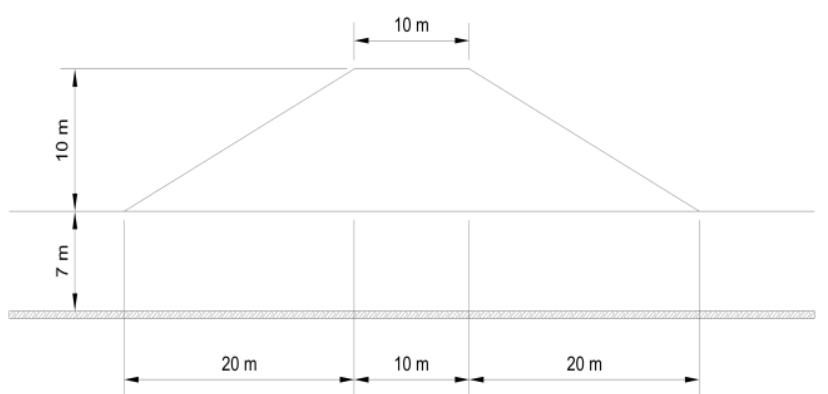

Figure 1 Example of geometry and soil properties in case of embankment stability

Basically, calculation or analysis of slope stability can be done manually or using geotechnical software. Manual computations are calculated using several methods such as Bishop, Taylor, Spencer, Fellenius, Morganstern and other methods. The whole method of 
manual calculation is based on the concept of equilibrium limit. Then, if using the software, the geotechnical software widely used and will be used in this research is Plaxis and Geoslope. The concept of calculation on Plaxis is based on the finite element method (FEM), while the concept of calculation on Geoslope is based on the concept of equilibrium limit.

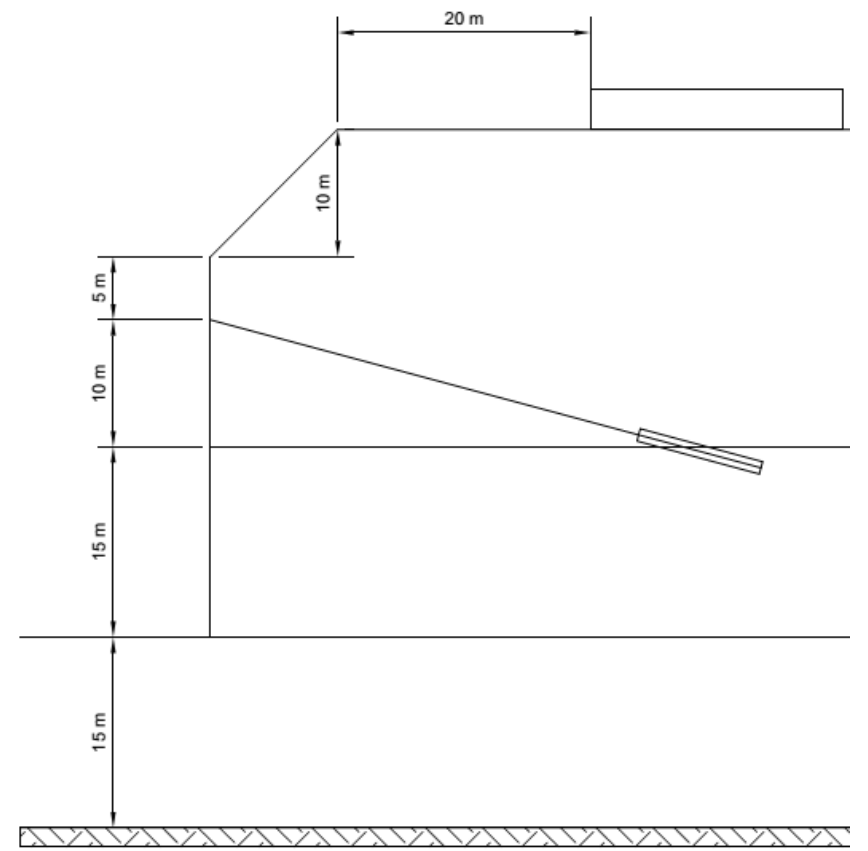

Figure 2 Sample case evaluation of slope stability with ground anchor

\subsection{Basic Concept of Ground Movement Evaluation}

Ground movement is an effect that can actually be expected in a bridge project. Ground movement on a bridge can be caused by several things, among others:

- Road traffic load

- Earthquake

- Land consolidation

- Abutment instability

- Open-cut work around the location of the bridge

- Unstable ground conditions

Traffic load on a bridge is already planned for the maximum load that occurs, but sometimes in a time, the maximum load continues to occur and combined with other causal factors such as unstable ground conditions, then soil displacement in the bridge can occur. For the case of bridges built on soft soils, the displacement due to primary consolidation becomes a major issue. Primary consolidation results from the dissipation of pore water on the soil. In case of pore water dissipation, the volume of soil will shrink and there will be soil displacement.

Another cause of of ground movement is earthquake. Basically, the earthquake load has been included into the calculation process, but sometimes the earthquake that occurs exceeds the prediction in the calculation. If that happens, then the displacement of the soil beyond predicted value can not be avoided. Then, instability of the slope at the abutment of bridge causes displacement in that location. Open excavations or opencut conducted around the location of the bridge will also cause soil displacement around the bridge. Open excavations are often done during the construction period. Open excavations during the actual operation of the bridge should be avoided as much as possible.

The most common characteristic that can be observed when sub-structure of bridges displaced beyond the predicted value is by observing the condition of bridge structural elements (such as pier condition, beam and bridge deck). Another feature is to observe unnatural movements in the ground around the location of the bridge. Another case is to observe the overall geological conditions that allow the movement of the soil around the bridge, such as the case of bridges located in the basin or valley whose slopes are steep and unstable; If the slopes around the basin or valley move significantly, then the soil around the bridge base can move anyway.

\subsection{Basic Concept of Fuzzy AHP Method for Assessing Bridge Substructure Condition}

Fuzzy AHP method is based on Fuzzy logic developed by Lotfi Zadeh in 1965. Fuzzy logic itself is a component in the formation of soft computing. Fuzzy logic consists of sets which are then called Fuzzy sets. In Fuzzy sets, each member in a Fuzzy set has its own value known as the membership degree or membership function. In everyday life applications, Fuzzy logic is used to map problems from input data to expected output data (Kusumadewi, 2010).

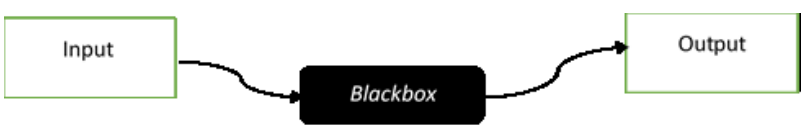

Figure 3 Simple mapping of input-output process

In Figure 3, there is a "blackbox" box between the input box and the output box. The blackbox can be designated as Fuzzy logic. Clearly, the blackbox turns the input box into an output box. The blackbox contains the methods or set of rules used to process the input data into output data. Here are some reasons according to Cox (1994) regarding the use of Fuzzy logic:

- Fuzzy logic concept is relatively easy to understand. This is because Fuzzy logic uses the basic set theory, so the mathematical concepts underlying fuzzy reasoning will be easy to understand.

- Flexibility of Fuzzy logic. Fuzzy logic is able to adapt to the changes and uncertainties that accompany the problem. 


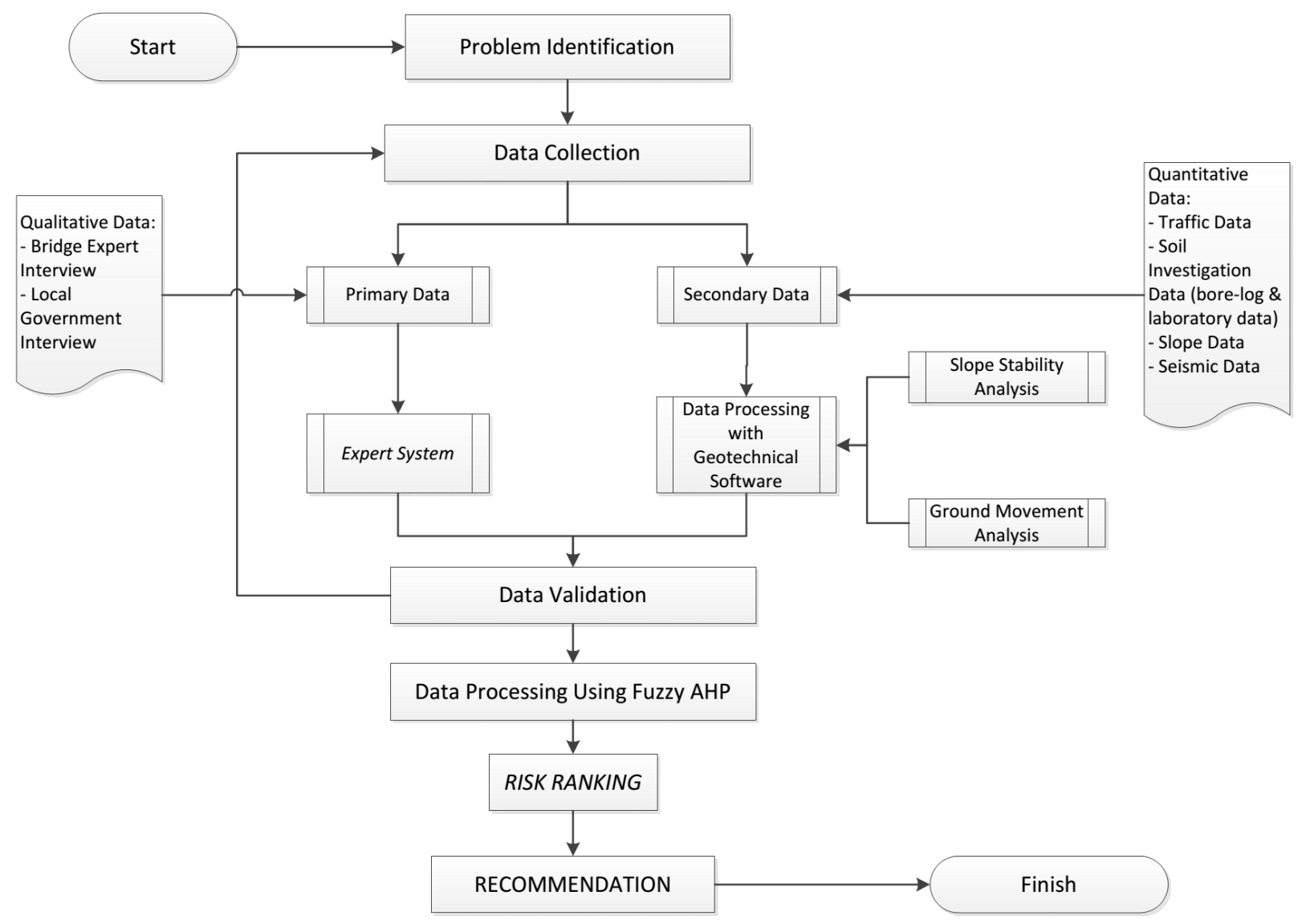

Figure 4 Research Flowchart

- High level of tolerance to exclusive data. If in a homogeneous set of data, then there is one exclusive data (different data from the other data itself), then Fuzzy logic is able to handle that exclusive data.

- Non-linear modeling. Fuzzy logic is able to model non-linear functions

- Inclusion expert experience. In Fuzzy logic, expert experience will be included and become an important component in Fuzzy logic

- Relatively wide application in engineering scope

- The use of natural language which is relatively easy to understand

In contrast to bivalent logic which is an absolute value between 0 or 1 . Choice of value is only absolute value 0 (zero) or 1 (one). If it is not a value of 0 , then its value should be 1 and vice versa. The absolute value will cause inaccuracy for a certain range of data. In Fuzzy logic, there is no absolute value, there is an absolute limit. The absolute limit in Fuzzy logic is 0 and 1. The value belonging to the data into membership function is the value that is in the range 0 to 1 . The value can be 0.1 , $0.25,0.931$ and so on.

\section{Overview in Analyzing and Designing Fuzzy System Using Fuzzy Toolbox in MatLab Enviromnment}

MATLAB software is a very powerful tool with various toolbox that accompany it. MATLAB is widely used to solve mathematical problems with graphic illustrations. Basically, MATLAB is an executable programming language-based software. MATLAB has both built-in and add-on toolboxes. Especially for data processing with Fuzzy AHP method, the use of toolbox in the form of Fuzzy Toolbox becomes obligation. Fuzzy Toolbox is an add-on that must be purchased separately on the Mathwoks website (MATLAB publisher); This is because Fuzzy Toolbox does not become the built-in toolbox in MATLAB.

In Fuzzy Toolbox, there is a system called Fuzzy Inference System (FIS). This FIS is the "blackbox" as described in the previous section. FIS is in charge of inference of input data provided. FIS has several derived functions, namely:

- FIS Editor (as sub-function input inference)

- Rule Editor (as sub-function input inference)

- Membership Function Editor (as input sub-function input)

- Rule Viewer (as output sub-function and readonly)

- Surface Viewer (as output sub-function and readonly) 


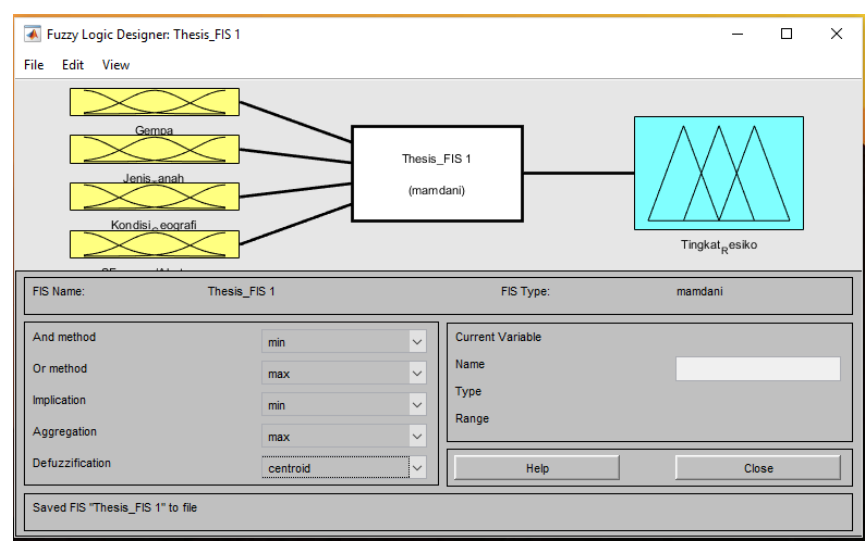

Figure 5 FIS Editor Interface

\section{Research Instrument}

This study uses a variety of research instruments. This diverse research instrument is based on differences in the two types of data to be used in the study. Two types of data used are qualitative data (which later will form expert system) and quantitative data (in the form of analysis of slope stability and ground movement).

For qualitative data, this type of data will be primary data. The instrument used in order to obtain this primary data is by interview. Respondents who were used as resource persons in the interviews were predetermined bridge experts (purposive sampling). The interview will use a questionnaire and will be done at the site where the respondent reside or work The bridge experts who will be the respondents are experts who served in various institution, such as:

- Ministry of Public Works

- Teachers / lecturers at the University or Institute

- Professional or practitioner

There are several questions that will be asked as a list of questions. Here's an outline of the list of questions to be made:

- The general condition of the bridge (especially the sub-structural component) in the region $\mathrm{x}$

- Frequency of maintenance / repair / rehabilitation of bridges (including sub-structural components) within one-budget year

- Funds that should be provided for the maintenance and / or rehabilitation of bridges (especially substructural components)

- Damage that often occurs in structural components under the bridge

- The response time between the damage with the repair effort

For qauntitative data, this type of data will be secondary data. The instrument used to obtain this secondary data is by working with third parties who have the data. This data is an archive owned by a third party. The researcher will use the archive data in accordance with the given permission. The secondary data plan to be used is:

- Bor-log data (Standard Penetration Test, SPT). This data was obtained from a third party conducting a geotechnical investigation on the bridge project under study. Typical geotechnical investigation data for bridge projects will include SPT, CPT and laboratory data. Data sources can be individual, consultant planners, contractors, ground mechanics laboratories, project owners and others

- Cone Penetration Test (CPT). This data will be obtained simultaneously with SPT data

- Laboratory data. This data will be obtained simultaneously with SPT data

- Geological data. Geological data obtained from the government agency (Geospatial Information Agency) that organizes geological mapping for the area around the bridge that became the object of research.

- Seismic data. Seismic data is obtained from the Center for Settlement Development (Puskim). The seismic data will be the spectral design at the location of the bridge studied. The data contained in Puskim is detailed up to the location coordinates, so that the spectral data of the earthquake can be more specific and precession.

\section{Sampling Design}

Sampling design to be conducted by researchers is as follows:

- Population. The population here is in the form of existing bridges in Java Island (with administrative area of Banten Province, Jakarta, West Java, Central Java, Yogyakarta and East Java).

- Samples. Researchers will conduct samples with targets of 5 to 10 bridges with medium span to long span bridges. Sampling of the bridge will be done randomly. The type of bridge under study will adjust to the availability of secondary data, so there is no reference to the number of bridges per province. It could be one province taken two or three samples whereas in other provinces not taken sampling due to the absence of data. Sampling will be done randomly and following the availability of third party data.

- Variables. For the variables in the sample, the constituent material of the bridge sub-structure component will be differentiated into concrete and steel with varying degrees of damage. 


\section{Data Processing}

Data processing to be conducted by researchers is as follows:

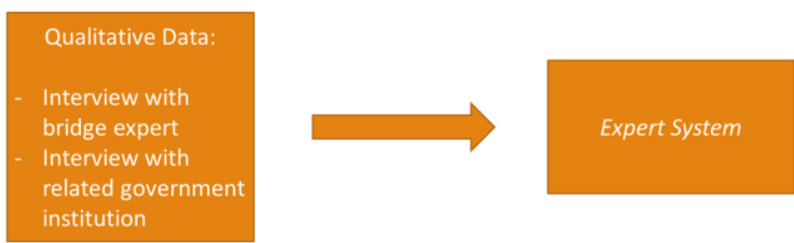

Figure 6 Qualitative Data Processing

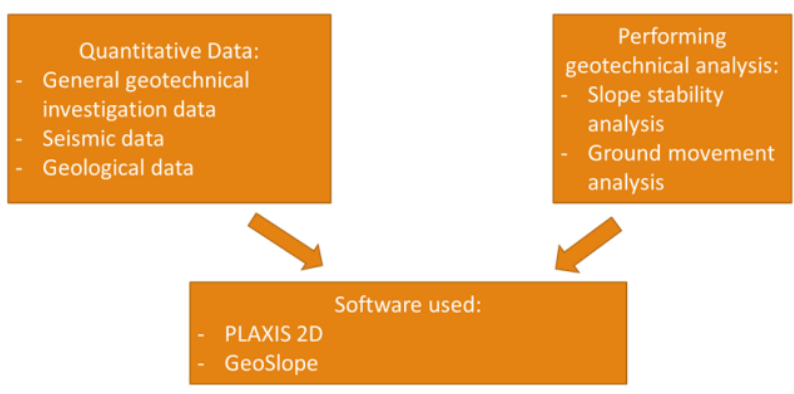

Figure 7 Quantitative Data Processing

\section{Conclusion}

In this research, Fuzzy AHP will be used to assess all possible hazard in the sub-structure of bridges. General geotechnical aspects will be analyzed. Authors propose Fuzzy AHP method to classify, conduct risk rating and assess the sub-structure of bridge. The end product will be risk or hazard classification of each bridge. This assessment can be a tool or recommendation for local government where the bridge located. Local goverment may able to make decision making process more precise and faster. More precise and faster the decision made the better bridge will be saved. The research is conducted for several bridges in Java Island, Indonesia.

\section{References}

1. An, Min et al, A Fuzzy Reasoning anf FuzzyAnalytical Hierarchy Process Based Approach to the Process of Railway Risk Information: A Railway Risk Management System, Information Sciences 181, pp. 3946-3966 (2011)

2. Attaway, Stormy, MATLAB: A Practical Introduction to Programming and Problem Solving, Oxford - UK: Bitterworth - Heinermann - Elsevier Inc. (2009)

3. Andric, Jelena M. et al, Risk Assessment of Bridges Under Multiple Hazards in Operation Period, Journal of Safety Science - Elsevier 83, pp. 80-92 (2016)

4. Carbonari, Sandro et al, Soil-Structure Interaction Effect in Single Bridge Piers Founded on Inclined Pile Groups, Soil Dynamics and Earquake Engineering 92, pp. 52-67 (2017)
5. Cook, Wesley et al, Bridge Failure Rate, Journal of Performance of Constructed Facility 29, pp. 1-8 (2015)

6. Corotis, Ross B., An Overview of Uncertainty Concepts Related to Mechanical and Civil Engineering, Journal of Risk and Uncertainty in Engineering System Vol. 1, pp. 1-12 (2015)

7. Craig, Robert F., Soil Mechanics, $7^{\text {th }}$ edition, New York - USA: Spon Press (2004)

8. Duncan, J. M. and Stephen G. Wright, Soil Strength and Slope Stability, New Jersey - USA: John Wiley $\&$ Sons Inc. (2005)

9. Fagundes, Diego F. et al, Load Transfer Mechanism and Deformation of Reinforced Piled Embankment, Geotextiles and Geomembranes 45, pp. 1-10 (2017)

10. Kusumadewi, Sri et al, Fuzzy Multi-Attribute Decision Making (Fuzzy MADM), Yogyakarta Indonesia: Penerbit Graha Ilmu (2006)

11. Kusumadewi, Sri, Analisis \& Desain Sistem Fuzzy Menggunakan Toolbox Matlab, Yogyakarta Indonesia: Penerbit Graha Ilmu (2002)

12. Aplikasi Logika Fuzzy Untuk Pendukung Keputusan, $2^{\text {nd }}$ edition, Yogyakarta - Indonesia: Penerbit Graha Ilmu (2010)

13. Lee, Sangwook, Determination of Priority Weight Under Multi-Attribute Decision-Making Situation: AHP versus Fuzzy AHP, Journal of Construction Engineering and Management 141, pp. 1-9 (2015)

14. Marwoto, Sofa, Pemodelan Sistem Pendukung Keputusan Untuk Pemeliharaan Jembatan Beton, Jurnal Teknik Sipil, Volume II No. 1 (2014)

15. Maula, B. H. and Zhang, L., Assessment of Embankment Factor of Safety Using Two Commercially Available Programs in Slope Stability Analysis, Procedia Engineering 14, pp. 559-566 (2011)

16. Nezarat, Hamidreza et al, Ranking of Geological Risks in Mechanized Tunneling by Using Fuzzy Analytical Hierarchy Process (FAHP), Tunneling and Underground Space Technology 50, pp. 358364 (2015)

17. Patel, D. A. et al, Hazard Assessment Using Consistent Fuzzy Preference Relation Approach, Journal of Construction Engineering and Management 142, pp. 1-10 (2016)

18. Senouci, Ahmed et al, Fuzzy-Based Model for Predicting Failure of Oil Pipelines, Journal of Infrastructure System 20, pp. 1-11 (2014)

19. Zadeh, Lotfi A., Is There a Need for Fuzzy Logic, Journal of Information Sciences No. 178, pp. 27512779 (2008)

20. Zatar, W. A. et al, Bridge Embankment. I: Seismic Risk Assessment and Rating, Journal of Performance of Constructed Facility 22, pp. 171-180 (2008) 